\title{
Impact of infection in hospitalized cirrhotic patients in a university hospital
}

\author{
Tiago dos Santos Ferreira', Tiago Sevá-Pereira ${ }^{1,2}$, Jazon Romilson de Souza Almeida, ${ }^{1,2}$, \\ Milena Fioravante $^{1^{*}}$, Ademar Yamanaka ${ }^{1,2}$, Elza Cotrim Soares ${ }^{1,2}$ \\ ${ }^{1}$ Department of Internal Medicine, Faculty of Medical Sciences, University of Campinas (UNICAMP), Campinas, Brazil \\ ${ }^{2}$ Gastrocenter, University of Campinas (UNICAMP), Campinas, Brazil \\ Email: cotrim@unicamp.br, ․ㅡㄴ fioravante@yahoo.com.br
}

Received 13 June 2012; revised 15 July 2012; accepted 28 July 2012

\begin{abstract}
Background: Infection increases the morbidity and mortality in liver cirrhosis patients. The aim of this study was to investigate the impact of infection related to survival and risk factors for death in adult patients with liver cirrhosis in a university hospital. Methods: In a retrospective cohort study of Brazilian hospitalized cirrhotic patients, medical records data were analysed, and all patients who have had one or more confirmed bacterial infection during admission were selected for the study. Also, some data as biochemical investigation, Child score, MELD estimation, and evolution and death event were included. Statistical analysis: chi-square, Fisher and Mann-Whitney tests were used. Uni and multivariate analysis were performed, according to Cox regression model. The significant statistical level was $p<0.05$. Results: In a total of 1221 medical records of hospitalized cirrhotic patients, 107 of them presented the diagnoses of infection. Evolution for death occurred in $29 \%$ of patients. The most common infections were spontaneous bacterial peritonitis $(32.7 \%)$, urinary tract infection $(31.8 \%)$ and pneumonia (15.9\%). Spontaneous bacterial peritonitis $(p<0.027)$, ascites $(p<0.024)$, upper gastrointestinal bleeding $(p<0.039)$ were related with death outcome as well as MELD $(p<0.004)$, increased serum creatinine $(p<0.021)$, and low serum sodium $(p<$ 0.010). Patients who had serum sodium $<130 \mathrm{mEq} / \mathrm{L}$, upper gastrointestinal bleeding episodes and serum creatinine $>2.5 \mathrm{mg} / \mathrm{dl}$ had increased the risk of death of 4.1, 3.2 and 3.2, respectively. Conclusion: Bacterial infections in hospitalized cirrhotic patients deserve special care, mainly spontaneous bacterial peritonitis, and also patients whose hiponatremia, upper gastrointestinal bleeding, high levels of creatinine and MELD high score are found.
\end{abstract}

"Corresponding author.
Keywords: Infection; Survival Curve; Mortality; Liver Cirrhosis

\section{INTRODUCTION}

Infection in liver cirrhosis patients is very common and results many times in hospitalization of the patients, and sometimes leading to death [1-7]. Some of the mechanisms that explain the largest susceptibility of that population to infection, are neutrophil dysfunction, diminished activity of monocytes and macrophages, and reduced opsonification against pathogens [8]. Other factors such as malnutrition, upper gastointestinal bleeding (GIB), and impairment in immunodefense mechanisms favour infection [4-6,8-11].

Bacterial translocation (BT) is a mechanism that contributes to the high prevalence of bacterial infection in cirrhotic patients, mainly to spontaneous bacterial peritonitis (SBP) $[9,10,12,13]$.

A recent study showed that during the last few decades, mortality rates have remained unchanged in different bacterial infections in cirrhotic patients, except SBP, that has decreased from $67 \%$ to $37 \%$ [3]. Mesquita et al., França et al. [14-16] have given emphasis to a better understanding of patients with SBP, especially related to therapeutic effectiveness analyses. In order to adopt significant prophylactic measures it is worth to have an extensive study of infectious complications in cirrhotic patients.

The aim of this study was to evaluate the impact of bacterial infections in cirrhosis patients, related to mortality and its risk factors at a Brazilian university hospital in the recent past.

\section{PATIENTS AND METHODS}

This was a retrospective cohort of data acquired from a clinical protocol, based on infection's events in hospitalized cirrhotic patients, implemented for all patients undergoing hospitalization between January 2006 and December 2007 in a university hospital in Campinas, Sao 
Paulo, Brazil.

From the total records reviewed, all those cirrhotic patients who presented one or more episodes of infection were selected for inclusion on the study. So, inclusion criteria were: to be hospitalized, have liver cirrhosis diagnosed, both genders, between 18 and 85 years old. After these conditions were attempted, the next criteria were to present one or more bacterial infection during hospitalization.

Exclusion criteria were: if the patients don't have liver cirrhosis diagnosed, and not to be hospitalized on the studied period.

Patients were studied according to the age, gender, type of infection, length of stay (time of hospitalization), associated diseases, etiologic agent of infection and the evolution to medical discharge or death, furthermore, survival at the hospital, in days.

In the Protocol of the study, the following laboratory tests were included: International Normalized Ratio (INR), serum creatinine, bilirubin, albumin, sodium, AST, ALT, gamma GT, alkaline phosphatase (ALP), and complete blood count. Also urine I, uroculture, blood culture, the analysis of ascites (white blood cell count, cytology, culture) and culture of different secretions were performed

The results of radiological examinations were evaluated, mainly X-ray of the chest, and abdominal ultrasound. To determine the severity of liver disease, Child-PughTurcotte [17,18] and MELD (Model for End-Stage Liver Disease) scores were used in all the patients $[19,20]$.

The MELD estimation were calculated in all the patients by using the results of INR, billirubin and creatinine of each patient, and corresponding to the infection period, through the model of UNOS, that can be found in a specific website (www.unos.org.br). The liver disease was considered more advanced as higher was the numerical final result obtained by the equation $[19,20]$.

The diagnostic of SBP was established when the count of polymorphonuclear in ascites fluid was more than 250 cells $/ \mathrm{mm}^{3}$. The result of the ascites fluid or blood culture was used to define the etiologic agent and not necessarily for diagnose of SBP $[14,21]$.

Urinary tract infection was defined by the presence of characteristic symptoms and/or bacterial growth in urine culture of more than 100,000 colonies $/ \mathrm{ml}$.

Respiratory infection was determined by clinical history, laboratory and radiological examinations.

However, the dermatologic infections were diagnosed from conventional protocols. Possible fungal and virus infections were diagnosed according to conventional standards.

Spontaneous bacteremias were confirmed finding two blood cultures positive for the same bacterial agent in the absence of any infectious focus or central intravascular catheter.
Antibiotic therapy was administrated in all patients according to our hospital protocol, and mainly in SBP already mentioned in previous studies [14-16].

\section{Statistical Analysis}

The values are reported as means \pm standard deviations. The significant level for statistical tests was $5 \%(\mathrm{p}<0.05)$. The chi-square test for the comparison of dichotomous data, and Fisher and Mann-Whitney tests for nonparametric data were used.

To analyze the factors related to death of cirrhotic patients logistic regression analysis was applied, with univariate and multivariate models, and Stepwise criterion of selection of variables were adopted.

Patients' mortality was calculated, and the survival curve obtained by using Kaplan-Meier method [22]. The factors associated with survival time were used for the analysis of Cox regression with univariate and multivariate models, as well as Stepwise criterion of variable selection [23].

For statistical analysis the following softwares were used:

- The SAS System for Windows (Statistical Analysis System), version 9.1.3.

SAS Institute Inc, 2002-2003, Cary, NC, USA.

- SPSS for Windows (Statistical Package for the Social Sciences), version 10.0.7.

SPSS Inc., 1989-1999, Chicago, IL, USA.

\section{RESULTS}

In the period of study from January 2002 to December 2006, 1947 patients were admitted to the Gastroenterology Infirmary ward, in the Clinical Hospital of Unicamp. Of that total number, 1221 patients have had liver cirrhosis diagnosed, 107 patients $(8.76 \%)$ have confirmed 137 infectious episodes at that time (11.2\%). From the patients, 75 were males $(70 \%)$ and 32 females $(30 \%)$ (Figure 1). The mortality rate during hospitalization was $29 \%$.

The characteristics, clinical and laboratory data of patients with infection and cirrhosis are described in Table 1.

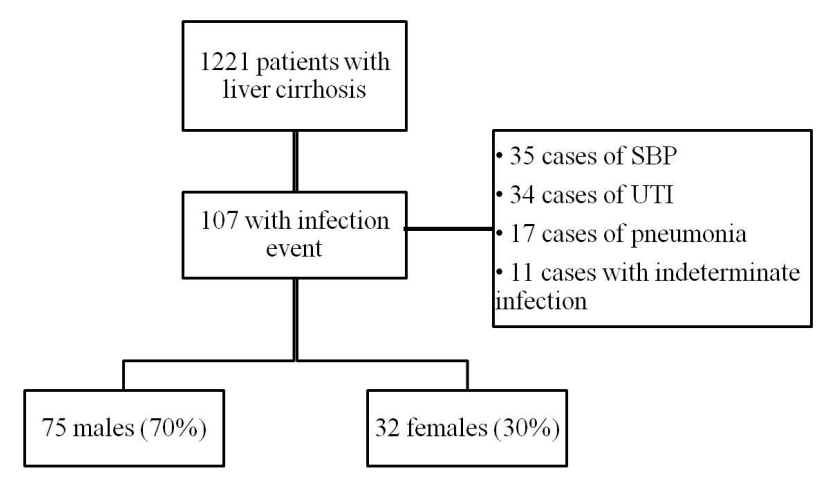

SBP: spontaneous bacterial peritonitis; UTI: urinary tract infection.

Figure 1. Flowchart of cirrhotic patients. 
Table 1. Characteristics, clinical and laboratory data of patients with infection and cirrhosis $(\mathrm{n}=107)$.

\begin{tabular}{cccccccc}
\hline VARIABLE & MEAN & S.D. & MIN & Q1 & MEDIAN & Q3 & MAX \\
\hline AGE & 52.89 & 12.94 & 21.00 & 44.00 & 53.00 & 60.00 & 85.00 \\
MELD & 19.42 & 8.10 & 4.70 & 13.82 & 17.76 & 24.13 & 44.54 \\
LENGTH OF STAY & 14.11 & 11.44 & 1.00 & 5.00 & 11.00 & 20.00 & 60.00 \\
ALBUMIN & 2.38 & 1.10 & 0.20 & 1.90 & 2.55 & 3.20 & 4.30 \\
INR & 1.85 & 0.58 & 1.00 & 1.48 & 1.73 & 2.03 & 4.38 \\
CREATININE & 1.58 & 0.92 & 0.27 & 1.00 & 1.15 & 1.90 & 4.74 \\
BILLIRUBIN & 4.62 & 7.04 & 0.10 & 1.33 & 2.27 & 4.76 & 40.39 \\
SERUM SODIUM & 134.8 & 8.46 & 113.00 & 131.00 & 135.00 & 139.00 & 193.0 \\
PLATELETS & 121.800 & 94.11 & 12.00 & 60.00 & 100.00 & 154.00 & 572.00 \\
\hline
\end{tabular}

INR = International Normalized Ratio.

The most frequent bacterial infections were:

- 35 cases of spontaneous bacterial peritonitis (32.7\%).

- 34 cases of urinary tract infection (31.8\%).

- 17 cases of pneumonia (15.9\%).

- 11 cases without any infected focus determined, although a clinical and laboratory diagnosis of infection was permanently founding ( $8 \%$ ). In that case, clinical and laboratorial diagnosis of infection always was made.

- Other events including infectious cellulitis, epididymitis, upper airway infections also have been found.

In $66.36 \%$ of infections, it was possible to determine the etiologic agent. The etiologic agents were $S$. aureus, Streptococcos sp., E. faecalis, S. epidermidis, E. clocae, E. faecium, E. aerogenes, P. mirabilis, P. aeuroginosa, among others, responsible for $68.22 \%$ of infections. Only 2 etiologic agents stood out:

- E. coli, responsible for $19.63 \%$ of infections.

- Klebsiela pneumonie, responsible for $12.15 \%$ of infections.

The chi-square test showed tha the presence of SBP (p $<0.027)$, ascites $(\mathrm{p}<0.024)$ and upper gastrointestinal bleeding $(\mathrm{p}<0.039)$ were related with death outcome as well as MELD $(p<0.004)$, increased serum creatinine ( $p$ $<0.021)$, and low serum sodium $(\mathrm{p}<0.010)$.

The Mann-Whitney test to analyze the relationship between continuous variables with death outcome was used. In the group of patients that not evolved to death, the mean values of MELD were lower than those in the group of patients who died during hospitalization $(17.5 \pm 7.3$ vs. $23.9 \pm 8.3 ; \mathrm{p}<0.001)$.

The length of stay in the group of patients who died was also higher $(12.5 \pm 11.4$ vs. $18 \pm 10.8 ; p=0.003)$.

Similarly, the values of INR, and serum creatinine and serum sodium were statistically different between death and no death outcomes (data not shown).

The results of the multivariate logistic regression analysis indicated that MELD score is a factor that influence in the death of the patients with liver cirrhosis. Patients with MELD score between 16 and 20 have 7.5 times the risk of death than those with MELD $\leq 15$, and patients with MELD $>20$ have 4.8 times the risk of death than those with MELD $\leq 15$ (Table 2).

The following Tables 3 and 4 are results from the analysis of Cox regression models, useful to study the relation between risk factors and survival of patients with liver cirrhosis. At first, the univariate analysis was performed (Table 3), and then multivariate analysis with stepwise criterion of selection of variables (Table 4).

From the results of multivariate analysis, we can infer the influence of some factors acting in the survival of patients with liver cirrhosis, such as: serum sodium levels (those with serum sodium $<130 \mathrm{mEq} / 1$ have 4.1 times higher death risk than those with sodium $\geq 130 \mathrm{mEq} / \mathrm{l}$ ), GIB (those who presented GIB episodes have 3.2 times death risk higher than those who didn't) and serum creatinine (those who presented serum creatinine $>2.5$ $\mathrm{mg} / \mathrm{dl}$ have a death risk 3.2 times higher than those who presented a serum creatinine $<1.5 \mathrm{mg} / \mathrm{dl}$ ) (Table 4).

In Figure 2, we can see (time hour sens) survival curves according serum sodium, bleeding episode and serum creatinine

\section{DISCUSSION}

Our data demonstrated the typical pattern of liver cirrhosis found in Brazil, concluding the predominance in males, with a mean age of 53 years. The prevalence rate $(8.7 \%)$ of bacterial infectious was lower than in other hospital units which range between $15 \%-25 \%$, and registered in prospective studies [24-28].

The distribution of different infections at the Unicamp Hospital closely followed the distribution in Mattos et al., who found urinary tract infection in $31.1 \%$ of the cases as the most prevalent, SBP in $25.9 \%$ of the patients, and then bronchopneumonia in $25.2 \%$ [24]. In the present study the results for UTI, SBP and pneumonia were $31.8 \%, 32.7 \%$ and $15.9 \%$, respectively. The occurrence 
Table 2. MELD score related to death outcome in patients with cirrhosis.

\begin{tabular}{ccccc}
\hline Variable & Categorias & $\mathrm{p}$ Value & O.R $^{\dagger}$ & IC 95\% O.R. \\
\hline \multirow{2}{*}{ MELD } & $\leq 15$ & - & 1.00 & - \\
& $16-20$ & $\mathbf{0 . 0 0 5}$ & 7.56 & $1.85-30.86$ \\
& $>20$ & $\mathbf{0 . 0 0 6}$ & 5.44 & $1.62-18.27$ \\
\hline
\end{tabular}

${ }^{\dagger}$ OR $($ Hazard Ratio $)=$ Ratio of risk for death; $(\mathrm{n}=63$ censorships $\mathrm{n}=28$ deaths). IC $95 \%$ OR $=$ range of $95 \%$ confidence for the ratio of risk. Stepwise criterion of selection of variables.

Table 3. Variables related to the length of survival (univariate analysis).

\begin{tabular}{|c|c|c|c|c|}
\hline Variable & Risk factors & $\mathrm{p}$ Value & H.R ${ }^{\dagger}$ & IC $95 \%$ H.R. ${ }^{\dagger}$ \\
\hline \multirow{2}{*}{ Gender } & Female (ref.) & - & 1.00 & - \\
\hline & Male & 0.986 & 0.99 & $0.46-2.17$ \\
\hline \multirow{3}{*}{ Age } & $<40$ years old & - & 1.00 & - \\
\hline & $40-59$ years old & 0.128 & 2.64 & $0.76-9.19$ \\
\hline & $\geq 60$ years old & 0.488 & 1.60 & $0.42-6.08$ \\
\hline \multirow{2}{*}{ Child } & $\mathrm{A}+\mathrm{B}$ & - & 1.00 & - \\
\hline & $\mathrm{C}$ & 0.722 & 1.19 & $0.46-3.05$ \\
\hline \multirow{3}{*}{ MELD } & $\leq 15$ & - & 1.00 & - \\
\hline & $16-20$ & 0.129 & 2.56 & $0.76-8.58$ \\
\hline & $>20$ & 0.051 & 3.00 & $0.99-9.02$ \\
\hline \multirow{3}{*}{$\begin{array}{c}\text { Spontaneous } \\
\text { bacterial peritonitis }\end{array}$} & No & - & 1.00 & - \\
\hline & Yes & 0.211 & 1.57 & $0.77-3.20$ \\
\hline & $>3.5$ & - & 1.00 & - \\
\hline \multirow[t]{3}{*}{ Albumin } & $2.8-3.5$ & 0.259 & 3.37 & $0.41-27.73$ \\
\hline & $<2.8$ & 0.214 & 3.59 & $0.48-27.03$ \\
\hline & $\leq 1.7$ & - & 1.00 & - \\
\hline \multirow[t]{3}{*}{ INR } & $1.8-2.3$ & 0.548 & 1.30 & $0.56-3.01$ \\
\hline & $>2.3$ & 0.748 & 1.17 & $0.46-2.96$ \\
\hline & $<1.5$ & - & 1.00 & - \\
\hline \multirow[t]{3}{*}{ Creatinine } & $1.5-2.5$ & 0.848 & 1.09 & $0.44-2.75$ \\
\hline & $>2.5$ & 0.046 & 2.36 & $1.02-5.49$ \\
\hline & $<2.0$ & - & 1.00 & - \\
\hline \multirow[t]{2}{*}{ Bilirubin } & $2.0-3.0$ & 0.253 & 1.85 & $0.65-5.28$ \\
\hline & $>3.0$ & 0.143 & 1.88 & $0.81-4.39$ \\
\hline \multirow{3}{*}{ Serum sodium } & $\geq 130$ & - & 1.00 & - \\
\hline & $<130$ & 0.11 & 2.72 & $1.26-5.84$ \\
\hline & $>130$ & - & 1.00 & - \\
\hline \multirow[t]{2}{*}{ Platelets } & $100-130$ & 0.057 & 3.01 & $0.97-9.32$ \\
\hline & $<100$ & 0.028 & 3.06 & $1.13-8.31$ \\
\hline \multirow{2}{*}{ Diabetes } & No & - & 1.00 & - \\
\hline & Yes & 0.824 & 0.89 & $0.31-2.57$ \\
\hline \multirow{2}{*}{$\begin{array}{l}\text { Gastrointestinal } \\
\text { bleeding }\end{array}$} & No & - & 1.00 & - \\
\hline & Yes & 0.014 & 2.56 & $1.21-5.41$ \\
\hline \multirow{2}{*}{ Ascites } & No & - & 1.00 & - \\
\hline & Yes & 0.019 & 4.22 & $1.27-14.01$ \\
\hline \multirow{2}{*}{$\begin{array}{l}\text { Hepato-renal } \\
\text { synrome }\end{array}$} & No & - & 1.00 & - \\
\hline & Yes & 0.138 & 1.91 & $0.81-4.47$ \\
\hline
\end{tabular}

${ }^{\dagger} \mathrm{HR}($ Hazard Ratio $)=$ Ratio of risk for death; $(\mathrm{n}=76$ censorships $\mathrm{n}=31$ deaths). IC $95 \% \mathrm{HR}=$ range of $95 \%$ confidence for the ratio of risk. Stepwise criterion of selection of variables. INR = International Normalized Ratio.
Table 4. Variables related to the length of survival (multivariate analysis).

\begin{tabular}{ccccc}
\hline Variable & Categories & p-value & H.R. $^{\dagger}$ & IC 95\% H.R. $^{\dagger}$ \\
\hline \multirow{2}{*}{ Serum sodium } & $\geq 130$ & - & 1.00 & - \\
& $<130$ & $\mathbf{0 . 0 0 3}$ & 4.06 & $1.59-10.37$ \\
Gastrointestinal & No & - & 1.00 & - \\
bleeding & Yes & $\mathbf{0 . 0 0 8}$ & 3.16 & $1.36-7.34$ \\
& $<1.5$ & - & 1.00 & - \\
Serum creatinine & $1.5-2.5$ & 0.801 & 0.88 & $0.33-2.34$ \\
& $>2.5$ & $\mathbf{0 . 0 1 8}$ & 3.24 & $1.22-8.58$ \\
\hline
\end{tabular}

${ }^{\dagger}$ HR $($ Hazard Ratio $)=$ Ratio of risk for death; $(n=63$ censorships $n=28$ deaths). IC $95 \% \mathrm{HR}=$ range of $95 \%$ confidence for the ratio of risk. Stepwise criterion of selection of variables.

of $29 \%$ of mortality during the hospitalization, also agreed with other studies, mainly in Brazil $[15,25,28]$. The most prevalent of the infections was the etiologic agent $E$. coli which confirms the national and international data $[5,6$, 16,26-27]. Nevertheless, some authors have mentioned a possible change in the etiologic pattern of SBP related to the increase in quinolone-resistent bacteria emergence [7].

SBP was the only infection that was associated with death and acted as a significant risk factor, increasing the chance 2.63 times $(95 \%$ CI $[1,6-10,27])$ [19,28]. This fact demonstrates the great importance of SBP compared to other type of infections, as mentioned above [26]. The main mechanism underlying the development of SBP, as well as other bacterial infections in cirrhosis, is represented by bacterial translocation from the intestinal lumen to mesenteric lymph nodes or other extraintestinal sites. This description means the passage of non-pathogenic bacteria, which normally colonize the gastrointestinal tract by the intestinal wall, infecting distant sites, such as mesenteric lymphnodes, spleen and liver. All this process is facilitated by several factors, including changes in intestinal flora, portal hypertension, gastrointestinal motility, and, mainly, impairment in local/systemic immune defense mechanisms, common factors in our patients [9,10,12,29-31].

On the other hand, autonomic dysfunction (AD) as occurs in patients with liver cirrhosis may also affect gastrointestinal motor activity, contributing to BT [32]. This situation was related either in alcoholic or more recently in non-alcoholic cirrhotic individuals, as was found in Nagasako's study at Unicamp [32,33]. So, the role of $\mathrm{AD}$ on that subject should be more investigated.

Bacterial infections in advanced cirrhosis contribute to a systemic inflammatory response, which can explain SBP. An exaggerated production of cytokines can activate vasodilating systems and generate reactive oxygen species [9]. Systemic and hepatic hemodynamics before and after a liquid test meal were assessed in a series of 75 noninfected patients with cirrhosis (55 with ascites) by Bernardi et al. [9] which bacterial DNA was detected only in patients with ascites. 


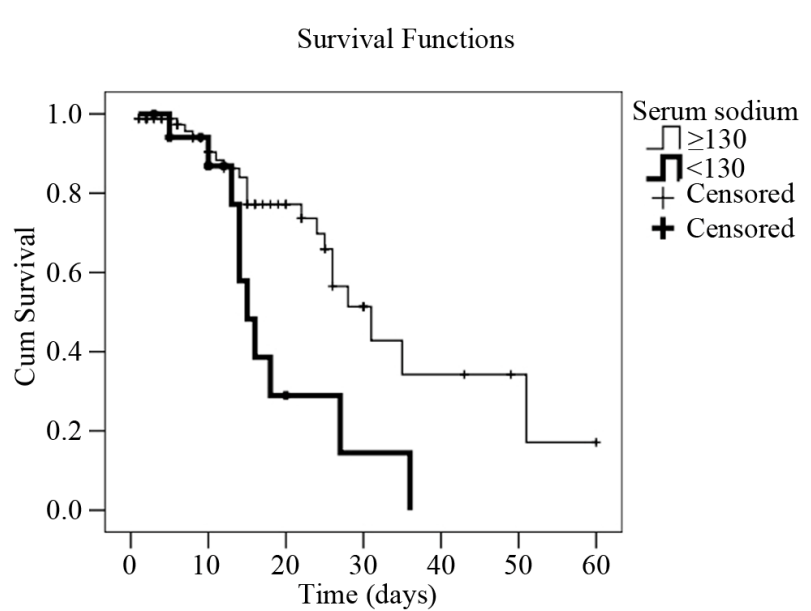

(a)
Survival Functions

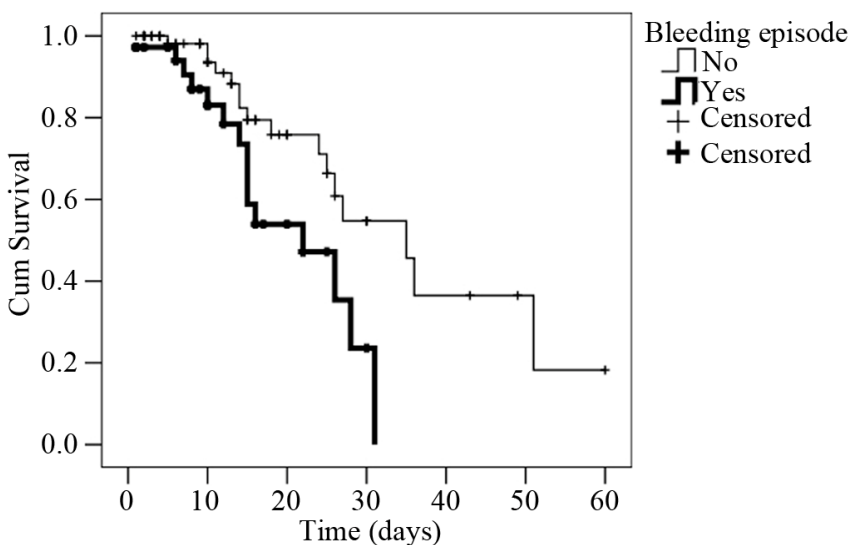

(b)

Survival Functions

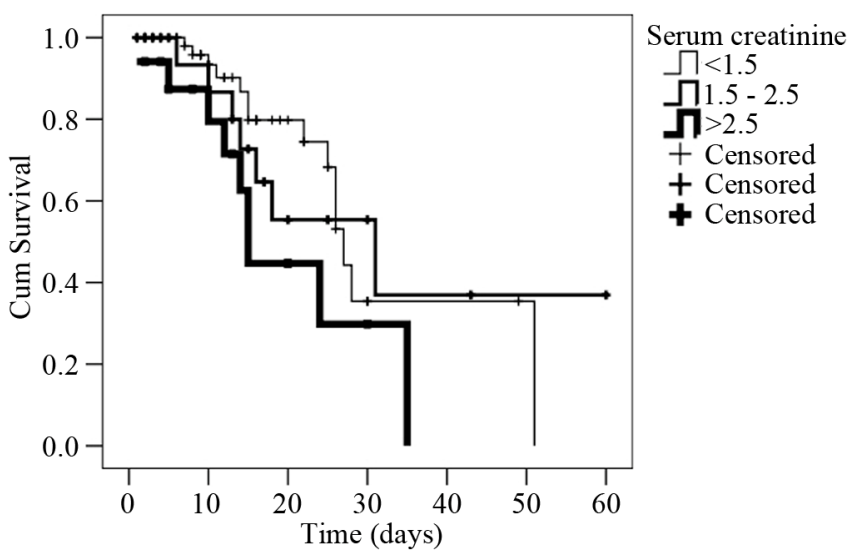

(c)

Figure 2. Survival curves in cirrhotic patients with infection (Kaplan-Meyer) expressed as their serum creatinine, and sodium values, as well as upper gastrointestinal bleeding episode. (a) Cumulative survival curve related to serum sodim values in cirrhotic patients with infection event. Patients with serum sodium $<130 \mathrm{mEq} / 1$ have 4.1 times higher death risk than those with sodium $\geq 130 \mathrm{mEq} / 1$ ( $\mathrm{p}$ $=0.003$ ); (b) Cumulative survival curve related to upper gastrointestinal bleeding in cirrhotic patients with infection event. Patients who presented upper gastrointestinal bleeding episodes have 3.2 times death risk higher than those who didn't $(p=0.008)$; $(c)$ Cumulative survival curve related to serum creatinine levels in cirrhotic patients with infection event. Patients with serum creatinine levels $>2.5 \mathrm{mg} / \mathrm{dl}$ have a death risk 3.2 times higher than those who presented a serum creatinine $<1.5 \mathrm{mg} / \mathrm{dl}(\mathrm{p}=0.018)$.

In this way, the presence of bacterial DNA in noninfected cirrhotic patients with ascites is associated with a marked inflammatory process in that report [9], including activation of the inducible form of nitric oxide synthase and release of nitric oxide. This phenomenon is similar to that observed in patients with SBP. Although the presence of bacterial DNA has been associated with an impaired prognosis, the hemodynamic alterations are still not totally clear. In cirrhotics the association between ascitic fluid bacterial DNA positive and the aggravation of peripheral vasodilation and worsening of intrahepatic endothelial dysfunction have been described only recently $[9,34]$. These facts should explain the mortality of SBP patients in our study.

UTI occurred in $31.8 \%$ of patients in this sample. It is postulated that the high incidence of UTI in patients with cirrhosis, especially those with ascites, is probably also related to residual urine volume and possible vesical dysfunction, found in these patients [35].

MELD was related to death in all tests performed, corroborating its clinical value $[19,20]$. The same has not happened with the Child-Pugh score, which has been used with great effectiveness in other studies $[19,20]$. Since this study is retrospective, the possibility of bias cannot be excluded in the evaluation of the actual status of the patient during hospitalization. Probably, the fact that the assessment was made at a University Hospital, lead us to believe that this type of bias would be diminished.

Some studies have shown that the presence of GIB is a 
predisposing factor for infection, and it is also known that GIB is associated with higher mortality [34,36-38]. Our study demonstrated that the presence of GIB is a negative factor for the prognosis of the survival of this population (Figure 2). The same happened with patients having low serum sodium and high levels of creatinine, indicating a significant worsening of renal function [39-42]. In this situation, survival was significantly lower (Figure 2).

Finally, we believe our study can contribute to a better understanding of the reality that occurs in one of the most serious complications of liver cirrhosis, i.e. the infection, and particularly SBP $[43,44]$. This may lead to the establishment of medical protocols that can prevent its emergence such as the use of antibiotics in patients with previous SBP or with upper GIB, even the introduction of EV albumin for some SBP groups whose risk for death is high. [34,45].

\section{REFERENCES}

[1] Garcia-Tsao, G. (2001) Current management of the complications of cirrhosis and portal hypertension: Variceal hemorrhage, ascites, and spontaneous bacterial peritonitis. Gastroenterology, 120, 726-748. doi:10.1053/gast.2001.22580

[2] Tandon, P. and Garcia-Tsao, G. (2008) Bacterial infections, sepsis, and multiorgan failure in cirrhosis. Seminars in Liver Disease, 28, 26-42. doi:10.1055/s-2008-1040319

[3] Merli, M., et al. (2010) Cirrhotic patients are at risk for health care-associated bacterial infections. Clinical Gastroenterology and Hepatology, 8, 979-985. doi:10.1016/j.cgh.2010.06.024

[4] Navasa, M., et al. (1998) Tumor necrosis factor and interleukin-6 in spontaneous bacterial peritonitis in cirrhosis: Relationship with the development of renal impairment and mortality. Hepatology, 27, 1227-1232. doi:10.1002/hep.510270507

[5] Caly, W.R. and Strauss, E., (1993) A prospective study of bacterial infections in patients with cirrhosis. Journal of Hepatology, 18, 353-358. doi:10.1016/S0168-8278(05)80280-6

[6] Bleichner, G., et al. (1986) Frequency of infections in cirrhotic patients presenting with acute gastrointestinal haemorrhage. British Journal of Surgery, 73, 724-76. doi:10.1002/bjs.1800730916

[7] Fernandez, J., et al. (2002) Bacterial infections in cirrhosis: Epidemiological changes with invasive procedures and norfloxacin prophylaxis. Hepatology, 35, 140-148. doi:10.1053/jhep.2002.30082

[8] Mehta, A.K. and Lyon, G.M., 3rd (2010) Infectious diseases in end-stage liver disease patients. Critical Care Nursing Clinics of North America, 22, 291-307. doi:10.1016/j.ccell.2010.04.002

[9] Bernardi, M. (2010) Spontaneous bacterial peritonitis: From pathophysiology to prevention. Internal and Emergency Medicine, 5, S37-S44. doi:10.1007/s11739-010-0446-x

[10] Cano, R., et al. (2010) Proteomic evidence of bacterial peptide translocation in afebrile patients with cirrhosis and ascites. Journal of Molecular Medicine (Berl), 88, 487-495. doi:10.1007/s00109-009-0582-9

[11] Christou, L., Pappas, G. and Falagas, M.E. (2007) Bacterial infection-related morbidity and mortality in cirrhosis. The American Journal of Gastroenterology, 102, 1510-1517. doi:10.1111/j.1572-0241.2007.01286.x

[12] Cirera, I., et al. (2001) Bacterial translocation of enteric organisms in patients with cirrhosis. Journal of Hepatology, 34, 32-37. doi:10.1016/S0168-8278(00)00013-1

[13] Steed, H., et al. (2011) Bacterial translocation in cirrhosis is not caused by an abnormal small bowel gut microbiota. FEMS Immunology \& Medical Microbiology, 63, 346-354. doi:10.1111/j.1574-695X.2011.00857.x

[14] Mesquita, M.A., et al. (1997) Ceftriaxone in the treatment of spontaneous bacterial peritonitis: Ascitic fluid polymorphonuclear count response and short-term prognosis. Hepato-Gastroenterology, 44, 1276-1280.

[15] Franca, A., et al. (2002) Five days of ceftriaxone to treat spontaneous bacterial peritonitis in cirrhotic patients. Journal of Gastroenterology, 37, 119-122. doi:10.1007/s005350200006

[16] Franca, A.V., et al. (2001) Long-term prognosis of cirrhosis after spontaneous bacterial peritonitis treated with ceftriaxone. Journal of Clinical Gastroenterology, 33, 295298. doi:10.1097/00004836-200110000-00007

[17] Child, C.G. (1964) The liver and portal hypertension. Major problems in clinical surgery. Saunders, Philadelphia, $231 \mathrm{p}$.

[18] Pugh, R.N., et al. (1973) Transection of the oesophagus for bleeding oesophageal varices. British Journal of Surgery, 60, 646-649. doi:10.1002/bjs. 1800600817

[19] Wiesner, R.H., et al. (2001) MELD and PELD: Application of survival models to liver allocation. Liver Transplantation, 7, 567-580. doi:10.1053/jlts.2001.25879

[20] Kamath, P.S., et al. (2001) A model to predict survival in patients with end-stage liver disease. Hepatology, 33, 464-470. doi:10.1053/jhep.2001.22172

[21] Rimola, A., et al. (2000) Diagnosis, treatment and prophylaxis of spontaneous bacterial peritonitis: A consensus document. International Ascites Club. Journal of Hepatology, 32, 142-153. doi:10.1016/S0168-8278(00)80201-9

[22] Kaplan, E.L. (1983) Citation classic-Nonparametric estimation from incomplete observations. Current Contents/Life Sciences, 24, 14.

[23] Christensen, E. (1987) Multivariate survival analysis using Cox's regression model. Hepatology, 7, 1346-1358. doi:10.1002/hep.1840070628

[24] Feldman, M., Friedman, L.S. and Sleisenger, M.H. (2002) Sleisenger \& Fordtran's gastrointestinal and liver disease: Pathophysiology, diagnosis, management. 7th Edition, Saunders, Philadelphia, $98 \mathrm{p}$.

[25] De Mattos, A.A., et al. (2003) Bacterial infection in cirrhotic patient. Arquivos de Gastroenterologia, 40, 11-15. 


\section{doi:10.1590/S0004-28032003000100003}

[26] Strauss, E. and de Sa Ribeiro Mde, F.G. (2003) Bacterial infections associated with hepatic encephalopathy: Prevalence and outcome. Annals of Hepatology, 2, 41-45.

[27] Strauss, E. and Aerosa, J.P. (2004) Alcoholic hepatitis: Bad prognosis due to concomitant bacterial infections. Revista da Sociedade Brasileira de Medicina Tropical, 37, 199-203. doi:10.1590/S0037-86822004000300001

[28] Moore, K.P. andAithal, G.P. (2006) Guidelines on the management of ascites in cirrhosis. Gut, 55, vi1-vi12. doi:10.1136/gut.2006.099580

[29] Maheshwari, A. and Thuluvath, P.J. (2005) Autonomic neuropathy may be associated with delayed orocaecal transit time in patients with cirrhosis. Autonomic Neuroscience, 118, 135-139. doi:10.1016/j.autneu.2005.02.003

[30] Chesta, J. and Defilippi, C. (1993) Abnormalities in proximal small bowel motility in patients with cirrhosis. Hepatology, 17, 828-832.

[31] Madrid, A.M., et al. (1998) Small bowel motility in primary biliary cirrhosis. The American Journal of Gastroenterology, 93, 2436-2440. doi:10.1111/j.1572-0241.1998.00700.x

[32] Moller, S., et al. (2007) Reduced baroreflex sensitivity in alcoholic cirrhosis: relations to hemodynamics and humoral systems. American Journal of Physiology-Heart and Circulatory Physiology, 292, H2966-H2972. doi:10.1152/ajpheart.01227.2006

[33] Nagasako, C.K., et al. (2009) Investigation of autonomic function and orocecal transit time in patients with nonalcoholic cirrhosis and the potential influence of these factors on disease outcome. Journal of Clinical Gastroenterology, 43, 884-889. doi:10.1097/MCG.0b013e31818de34c

[34] Bellot, P., et al. (2010) Bacterial DNA translocation is associated with systemic circulatory abnormalities and intrahepatic endothelial dysfunction in patients with cirrhosis. Hepatology, 52, 2044-2052. doi:10.1002/hep.23918

[35] Bercoff, E., et al. (1985) Urinary tract infection in cirrhotic patients, a urodynamic explanation. Lancet, 1, 987. doi:10.1016/S0140-6736(85)91764-7

[36] Almeida, D., et al. (2001) Comparative study of bacterial infection prevalence between cirrhotic patients with and without upper gastrointestinal bleeding. Brazilian Journal of Infectious Diseases, 5, 136-142. doi:10.1590/S1413-86702001000300006

[37] Bernard, B., et al. (1995) Prognostic significance of bacterial infection in bleeding cirrhotic patients: A prospective study. Gastroenterology, 108, 1828-1834. doi:10.1016/0016-5085(95)90146-9

[38] Vivas, S., et al. (2001) Presence of bacterial infection in bleeding cirrhotic patients is independently associated with early mortality and failure to control bleeding. Digestive Diseases and Sciences, 46, 2752-2757. doi:10.1023/A:1012739815892

[39] Fasolato, S., et al. (2007) Renal failure and bacterial infections in patients with cirrhosis: Epidemiology and clinical features. Hepatology, 45, 223-229. doi:10.1002/hep.21443

[40] Terg, R., et al. (2009) Serum creatinine and bilirubin predict renal failure and mortality in patients with spontaneous bacterial peritonitis: A retrospective study. Liver International, 29, 415-419. doi:10.1111/j.1478-3231.2008.01877.x

[41] Heuman, D.M., et al. (2004) Persistent ascites and low serum sodium identify patients with cirrhosis and low MELD scores who are at high risk for early death. Hepatology, 40, 802-810.

[42] Sort, P., et al. (1999) Effect of intravenous albumin on renal impairment and mortality in patients with cirrhosis and spontaneous bacterial peritonitis. The New England Journal of Medicine, 341, 403-409. doi:10.1056/NEJM199908053410603

[43] Deschenes, M. and Villeneuve, J.P. (1999) Risk factors for the development of bacterial infections in hospitalized patients with cirrhosis. The American Journal of Gastroenterology, 94, 2193-2197.

[44] European Association for the Study of the Liver (2010) EASL clinical practice guidelines on the management of ascites, spontaneous bacterial peritonitis, and hepatorenal syndrome in cirrhosis. Journal of Hepatology, 53, 397417. doi:10.1016/j.jhep.2010.05.004

[45] Kim, B.I., et al. (2011) Increased intestinal permeability as a predictor of bacterial infections in patients with decompensated liver cirrhosis and hemorrhage. Journal of Gastroenterology and Hepatology, 26, 550-557. doi:10.1111/j.1440-1746.2010.06490.x 